\title{
Acesso ao Saneamento básico e Incidência de Cólera: uma análise quantitativa entre 2010 e 2015
}

\author{
Access to basic and analytical sanitation of cholera: $a$ \\ quantitative analysis between 2010 and 2015
}

Everaldo de Santana Silva', Deloar Duda de Oliveira', Amanda Pontes Lopes ${ }^{\mathbf{1}}$

DOI: 10.1590/0103-11042019S309

RESUMO As condições de saneamento básico são um dos principais determinantes nos índices de agravos à saúde humana, principalmente no tocante a doenças infectocontagiosas por veiculação hídrica. Dentre todas, destacamos neste trabalho a cólera: doença entérica causada pelas cepas toxigênicas do Vibrio cholerae (sorogrupos O1 e O139), que é caracterizada por um quadro de acentuada diarreia. O objetivo deste trabalho, por meio de levantamento de dados mundiais de Incidência de Cólera (IC) e percentual populacional de Acesso ao Saneamento (AS), é quantificar, evidenciar e discutir a relação entre esses dois indicadores no período de 2010 a 2015, assim como apontar outros possíveis fatores magnificantes de vulnerabilidade socioambiental para a patologia. No período analisado, foram registrados 1.575 .168 casos da doença, com as maiores incidências na região do subcontinente áfrico-asiático e em países isolados nos demais continentes, como, por exemplo, Haiti (América) e Papua Nova Guiné (Oceania), que também apresentaram sérios problemas de acessibilidade a serviços de saneamento. Desta forma, apesar de sugerirmos a análise de outros fatores socioambientais, as condições de saneamento revelaram-se como um determinante expressivo para a incidência da cólera em todas as regiões do mundo.

PALAVRA-CHAVE Cólera. Vibrio cholerae. Saneamento básico. Doenças transmitidas pela água.

1 Universidade do Estado do Rio de Janeiro (Uerj) Rio de Janeiro (RJ), Brasil. everaldo.desantana@gmail. com
ABSTRACT Health conditions are among the main factors leading to human health damages, particularly concerning infectious diseases by water transmission. Among those cholera is highlighted in this work: the virus infection of Vibrio cholerae toxicity (serogroups O1 and O139), which is characterized by marked diarrhea. Using incidence data on cholera (CI) and the population percentage of Access to Sanitation (AS) collected throughout the world, the objective of this work is to quantify, highlight and discuss relationship between those two indicators over the period from 2010 to 2015, besides pointing out other possible magnifying factors of socioenvironmental vulnerability to this pathology. Over that period, 1,575,168 cases of the illness were analyzed, showing more frequent occurrences in the region of the African-Asian subcontinent and isolated countries in the other continents, such as Haiti (America) and Papua New Guinea (Oceania), which also presented serious problems regarding the access to sanitation services. Thus, although we suggest other socioenvironmental factors to also be analyzed sanitation conditions proved to be an expressive determinant for the incidence of cholera in all regions worldwide.

KEYWORD Cholera. Vibrio cholerae. Basic sanitation. Waterborne Disease. 


\section{Introdução}

Saneamento, segundo a Organização Mundial da Saúde ${ }^{1}$, é o controle de todos os fatores do meio físico do homem que exercem ou podem exercer efeitos nocivos sobre o bem-estar físico, mental e social - ou seja, é um conjunto de ações sobre $\mathrm{o}$ ambiente que visam a salubridade ambiental na prevenção e controle de doenças, promoção de saúde e qualidade de vida ${ }^{2}$.

O saneamento envolve ações primordiais e básicas de esgotamento sanitário, limpeza pública, drenagem urbana, controle de vetores e tratamento e abastecimento de água ${ }^{3}$. Estimase que $25 \%$ da população mundial não possuem acesso a habitação segura e serviços básicos, vivendo em condições ambientais e sanitárias precárias, criando um cenário negativo para o controle de surtos e epidemias 4 .

Aproximadamente $83 \%$ dos agravos à saúde e $23 \%$ das mortes prematuras são ocasionados por exposição a ambientes insalubres e saneamento deficiente ${ }^{5}$. Destes, as doenças diarreicas causam, em todo o mundo, quase 2,5 milhões de mortes anualmente, principalmente entre crianças com menos de cinco anos de vida em países em desenvolvimento $0^{6,7}$.

Doenças relacionadas ao sistema de água, por despejo de esgoto inadequado, geram milhões de mortes anualmente em países de baixa renda - Produto Interno Bruto (PIB) per capita inferior a US\$ 825,00, com ênfase em regiões de clima quente que experimentam situações tanto de inundações quanto de secas ${ }^{4}$. Segundo Feachem et al. ${ }^{\mathbf{8}}$, um único grama de fezes de indivíduos infectados pode conter cerca de $10^{6}$ vírus, $10^{8}$ bactérias, $10^{4}$ protozoários e $10^{4}$ ovos de helmintos patogênicos que, caindo em um sistema de saneamento deficiente, podem dar origem a processos de agravos à saúde local.

A prevalência dessas enfermidades representa um forte indicativo de fragilidade de políticas e da infraestrutura de saneamento ${ }^{9}$. Segundo Waddington e Snilstveit ${ }^{10}$, investimentos em saneamento poderiam reduzir em até $37 \%$ a ocorrência dessas enfermidades.
O processo epidemiológico de doenças transmissíveis envolve uma série de processos complexos, com várias determinantes sociais e econômicas. Na grande maioria das ocorrências, alterações de recursos hídricos causadas por problemas de saneamento e por poluição têm papel relevante na evolução dessas enfermidades ${ }^{3}$.

As situações econômicas e sociais exercem influência direta sobre a vulnerabilidade e a situação de saúde de um determinado extrato populacional cujas condições de vida acarretam intrinsecamente grande parte da carga de doenças ${ }^{11}$. Assim sendo, a saúde deve ser analisada como resultado de todas as variáveis ambientais, ou seja, os fatores naturais, sociais e econômicos que afetam as condições de vida, aumentando ou diminuindo a vulnerabilidade da população exposta, associando assim importância fundamental aos indicadores sociais de desenvolvimento nesta análise ${ }^{12}$.

Entre todas as doenças desencadeadas neste cenário, destacamos a cólera - doença entérica causada pelas cepas patogênicas do Vibrio cholerae $\mathrm{Ol}$ ou $\mathrm{O}_{139}{ }^{13}$, encontradas em ambientes aquáticos tanto em vida livre como parasitando organismos quitinosos, visto que apresentam função ecológica de degradação de quitina ${ }^{14,15}$.

Podem sobreviver em condições ambientais desfavoráveis por um período de tempo: o estado VNC (Viável, mas Não Cultivável), sugerindo esse processo como uma adaptação ambiental em regiões como altos níveis de salinidade, temperatura e $\mathrm{pH}^{16}$. De acordo com Mai et al. ${ }^{17}$, em estudos laboratoriais, as células no estado VNC podem permanecer viáveis por anos, e geralmente são encontradas na superfície de copépodos. Em contato com o intestino humano, no entanto, passam para o estado Viável (VC) ${ }^{\mathbf{1 8}}$.

A patogenicidade do microorganismo depende principalmente da expressão da toxina colérica e do píllus de colonização celular ${ }^{15}$, pois a virulência em humanos só é possível com a ingestão de no mínimo $10^{8}$ células, devido à acidez da região estomacal. De acordo com Figueiredo et al., ${ }^{19}$, a flexibilidade da aquisição da expressão gênica para 
a produção de toxina da cólera foi percebida pelo processo de transferência horizontal (conjugação), que é o processo de troca genética entre procariotas. Contribuindo mais para esta discussão, Rivera et al..$^{20}$ demonstrou um grande potencial de aquisição patogênica em indivíduos dos sorogrupos não O1 e não 0139.

A infecção em humanos se dá quando o vibrio é levado à boca, por mão suja ou pela ingestão de água ou alimentos lavados com água contaminada, ocasionando um quadro de intensa diarreia. Assim, a reposição de eletrólitos deve ocorrer rapidamente, a fim de impedir a evolução da condição grave da doença, que pode ocasionar a morte do indivíduo ${ }^{21}$.

No caso das doenças infectocontagiosas entéricas, entre elas a cólera, o indicador mais relevante é o saneamento 22 . Em países em desenvolvimento que apresentam infraestrutura sanitária precária, esta situação acaba por ocasionar altas taxas de morbidade e mortalidade oriundas dessas doenças, revelando vulnerabilidade dos sistemas e políticas públicas de saneamento e saúde ${ }^{23}$.

Assim sendo, conhecer regiões onde determinadas condições de risco ocorrem pode contribuir de maneira significativa para ações de prevenção e controle de doenças, quantificando e medindo a frequência com que os problemas de saúde ocorrem em populações humanas, e contribuindo para a construção de um arcabouço de ações de vigilância epidemiológica em saúde ${ }^{24}$.

$\mathrm{O}$ artigo tem como objetivo relacionar dados de Acesso ao Saneamento básico (AS) com a IC no período de 2010 a 2015, analisando o comportamento associativo entre estes dois parâmetros, e discutindo outros possíveis fatores magnificantes de vulnerabilidade para a patologia.

\section{Material e métodos}

Foram utilizados dados quantitativos secundários sobre IC entre os anos de 2010 a 2015 (seis anos), disponíveis no site da Organização Mundial da Saúde (OMS) ${ }^{25}$ (http://gamapserver.who.int/gho/interactive_charts/cholera/ atlas.html); e a verificação aos dados de AS, extraída do Banco Mundial ${ }^{26}$, disponíveis em http://databank.worldbank.org/.Esse intervalo de tempo foi escolhido por se confirmar como o período de maior surto da doença em todo o mundo durante todo o século XXI, principalmente na região das Américas.

Para melhor análise regional dos indicadores, procurou-se nas principais plataformas utilizadas como referência (OMS, Organização Pan-Americana da Saúde - Opas e Banco Mundial) um critério de regionalização dos países verificados. Apesar de conter processos classificatórios diferenciados, nenhuma delas representou os dados levantados com clareza, de forma quantitativa visual, o que impossibilitou uma visão efetiva da relação entre os indicadores.

Segundo o Instituto de Pesquisa Econômica Aplicada ${ }^{27}$, a regionalização é um desafio de ordem espacial, pois apresenta uma infinidade de fatores de agrupamentos que, dependendo do objetivo, devem construir elementos de visão e operação estratégicas para a análise, contendo, assim, elementos de subjetividade do classificador. Assim sendo, os países foram regionalizados por área (tabela 1) de acordo com a proximidade espacial e IC, para melhor análise da localização de picos de incidências.

Foram selecionados apenas os países: (i) com total IC igual ou maior que 18 (média de três/ano) em todo o período analisado; e (ii) com registro de AS em todo o período analisado.

Os países utilizados como ponto de discussão (determinados como críticos) foram os que revelaram IC acima de mil casos/ano e AS entre 1 e 50 por ano.

Fomentando a análise de outras vias e/ou outros fatores de vulnerabilidade, determinou-se como possível exceção a relação entre os dois indicadores propostos - ou seja, países que apresentaram elevada IC (IC>500) e com AS satisfatório (AS>80).

Todos os dados foram tabulados e analisados utilizando Microsoft Excel $2007^{\circledR}$. A Análise de Correlação de Pearson também foi realizada no mesmo software. 


\section{Resultados}

Foram selecionados 58 países, divididos em 12 áreas de análises, conforme as regras metodológicas no período do estudo. Registraram-se 1.667.058 casos de cólera, com destaque para os anos inicias de 2010 a 2012, que somaram 1.150.256 acometimentos (68,99\% de todo o período analisado). As IC, assim como a porcentagem da população com AS encontrados no período estão descritas na tabela 1.

\begin{tabular}{|c|c|c|c|c|c|c|c|c|c|c|c|c|c|c|}
\hline \multirow[t]{2}{*}{ Área } & \multirow[t]{2}{*}{ País } & \multicolumn{2}{|r|}{2010} & \multicolumn{2}{|r|}{2011} & \multicolumn{2}{|r|}{2012} & \multicolumn{2}{|r|}{2013} & \multicolumn{2}{|r|}{2014} & \multicolumn{2}{|r|}{2015} & \multirow{2}{*}{$\begin{array}{r}\text { Total } \\
\text { IC }\end{array}$} \\
\hline & & IC & AS & IC & AS & IC & AS & IC & AS & IC & AS & IC & AS & \\
\hline \multirow{12}{*}{$\begin{array}{l}\text { África } \\
\text { Central }\end{array}$} & Burkina Faso & 0 & 17,4 & 20 & 18 & 143 & 18,6 & 0 & 19 & 0 & 19,4 & 0 & 19,7 & 163 \\
\hline & Burundi & 333 & 46,9 & 1.072 & 47,2 & 214 & 47,5 & 1.557 & 47,8 & 582 & 48 & 442 & 48 & 4.200 \\
\hline & Chade & 6.395 & 11,6 & 17.267 & 11,8 & 0 & 12 & 0 & 12 & 0 & 12 & 0 & 12,1 & 23.662 \\
\hline & Etiópia & 1.682 & 21,7 & 0 & 23 & 0 & 24,3 & 0 & 25,5 & 0 & 26,8 & 0 & 28 & 1.682 \\
\hline & Malavi & 1.155 & 38,8 & 120 & 39,2 & 187 & 39,7 & 0 & 40,1 & 0 & 40,6 & 693 & 41 & 2.155 \\
\hline & Mali & 0 & 22,4 & 2.220 & 22,9 & 219 & 23,3 & 23 & 23,8 & 0 & 24,2 & 0 & 24,7 & 2.462 \\
\hline & Níger & 1.154 & 9,5 & 2.324 & 9,8 & 5.284 & 10,1 & 585 & 10,5 & 2.059 & 10,8 & 51 & 10,9 & 11.457 \\
\hline & $\begin{array}{l}\text { República } \\
\text { Central da } \\
\text { África }\end{array}$ & 0 & 20,7 & 117 & 21,1 & 21 & 21,1 & 0 & 21,6 & 0 & 21,7 & 0 & 21,8 & 138 \\
\hline & $\begin{array}{l}\text { República } \\
\text { Democrática } \\
\text { do Congo }\end{array}$ & 13.884 & 14,3 & 21.700 & 14,4 & 33.661 & 14,4 & 26.944 & 14,8 & 22.230 & 14,9 & 19.182 & 15 & 137.601 \\
\hline & Sudão do Sul & 0 & 6,5 & 0 & 6,6 & 0 & 6,6 & 0 & 6,7 & 6.421 & 6,7 & 1.818 & 6,7 & 8.239 \\
\hline & Uganda & 2.341 & 18 & 0 & 18,3 & 6.326 & 18,5 & 748 & 18,8 & 309 & 19 & 1.461 & 19,1 & 11.185 \\
\hline & Zâmbia & 6.794 & 42,8 & 330 & 43 & 198 & 43,2 & 0 & 43,5 & 0 & 43,7 & 0 & 43,9 & 7.322 \\
\hline \multicolumn{2}{|c|}{ TOTAL (12 Países) } & 33.738 & & 45.170 & & 46.253 & & 29.857 & & 31.601 & & 23.647 & & 210.266 \\
\hline \multirow{13}{*}{$\begin{array}{l}\text { África } \\
\text { Centro } \\
\text { Atlân- } \\
\text { tica }\end{array}$} & Angola & 1.484 & 46,2 & 1.810 & 47,6 & 1.215 & 49,1 & 6.655 & 50,6 & 213 & 51,1 & 0 & 51,6 & 11.377 \\
\hline & Benin & 983 & 17,3 & 755 & 17,8 & 625 & 18,4 & 528 & 19 & 832 & 19,6 & 0 & 19,7 & 3.723 \\
\hline & Camarões & 10.759 & 44,7 & 22.433 & 44,9 & 363 & 45,2 & 26 & 45,4 & 3.355 & 45,6 & 124 & 45,8 & 37.060 \\
\hline & Congo & 0 & 26,8 & 762 & 27,2 & 1.181 & 27,6 & 1.624 & 27,9 & 0 & 28,3 & 0 & 28,7 & 3.567 \\
\hline & $\begin{array}{l}\text { Costa do } \\
\text { Marfim }\end{array}$ & 32 & 20,9 & 1.261 & 21,3 & 424 & 21,6 & 56 & 22 & 235 & 22,3 & 199 & 22,5 & 2.207 \\
\hline & Gana & 438 & 13,7 & 10.268 & 14 & 9.548 & 14,4 & 50 & 14,7 & 28.944 & 14,8 & 692 & 14,9 & 49.940 \\
\hline & Guiné & 0 & 17,9 & 3 & 18,4 & 7.350 & 18,9 & 319 & 19,4 & 1 & 20 & 0 & 20,1 & 7.673 \\
\hline & Guiné Bissau & 0 & 18,9 & 0 & 19,6 & 3.068 & 20,2 & 969 & 20,5 & 11 & 20,7 & 0 & 20,8 & 4.048 \\
\hline & Libéria & 1.546 & 15,6 & 1.146 & 15,8 & 219 & 16,1 & 92 & 16,4 & 44 & 16,6 & 0 & 16,9 & 3.047 \\
\hline & Mauritânia & 0 & 35,7 & 46 & 36,9 & 0 & 38,2 & 0 & 39,5 & 0 & 39,7 & 0 & 40 & 46 \\
\hline & Nigéria & 44.456 & 30,5 & 23.377 & 30,2 & 597 & 29,9 & 6.600 & 29,6 & 35.996 & 29,3 & 5.290 & 29 & 116.316 \\
\hline & Serra Leoa & 0 & 12,6 & 0 & 12,7 & 23.124 & 12,8 & 377 & 13 & 0 & 13,1 & 0 & 13,3 & 23.501 \\
\hline & Togo & 72 & 9,5 & 4 & 9,8 & 61 & 10,1 & 166 & 10,5 & 262 & 10,8 & 35 & 10,9 & 600 \\
\hline \multicolumn{2}{|c|}{ TOTAL (13 Países) } & 59.770 & & 61.865 & & 47.775 & & 17.462 & & 69.893 & & 6.340 & & 263.105 \\
\hline
\end{tabular}


Tabela 1. (cont.)

\begin{tabular}{|c|c|c|c|c|c|c|c|c|c|c|c|c|c|c|}
\hline \multirow{4}{*}{$\begin{array}{l}\text { África } \\
\text { Índica }\end{array}$} & Quênia & 3.188 & 29,2 & 74 & 29,4 & 0 & 29,6 & 0 & 29,9 & 35 & 30,1 & 13.291 & 30,1 & 16.588 \\
\hline & $\begin{array}{l}\text { Moçambi- } \\
\text { que }\end{array}$ & 7.430 & 18,8 & 1.279 & 19,3 & 647 & 19,8 & 1.869 & 20,3 & 480 & 20,4 & 8.739 & 20,5 & 20.444 \\
\hline & Somália & 3.510 & 23,3 & 77.636 & 23,5 & 22.572 & 23,5 & 6.864 & 23,5 & 28.020 & 23,5 & 7.536 & 23,5 & 146.138 \\
\hline & Tanzânia & 4.469 & 13,1 & 942 & 13,6 & 286 & 14 & 270 & 14,5 & 0 & 15 & 11.563 & 15,6 & 17.530 \\
\hline \multicolumn{2}{|c|}{ TOTAL (04 Países) } & 18.597 & & 79.931 & & 23.505 & & 9.003 & & 28.535 & & 41.129 & & 200.700 \\
\hline $\begin{array}{l}\text { África } \\
\text { Centro } \\
\text { Meridional }\end{array}$ & Djibuti & 2.047 & 48,4 & 0 & 47,3 & 0 & 47,3 & 0 & 47,3 & 0 & 47,4 & 0 & 47,4 & 2.047 \\
\hline \multicolumn{2}{|c|}{ TOTAL (01 País) } & 2.047 & & 0 & & 0 & & 0 & & 0 & & 0 & & 2.047 \\
\hline \multirow{3}{*}{$\begin{array}{l}\text { América } \\
\text { Centro } \\
\text { Caribenha }\end{array}$} & Cuba & 0 & 91,7 & 0 & 92,2 & 417 & 92,7 & 181 & 93,1 & 76 & 93,2 & 0 & 93,2 & 674 \\
\hline & Haiti & 179.379 & 25,9 & 340.311 & 26,3 & 112.076 & 26,7 & 58.809 & 27,1 & 27.753 & 27,4 & 36.045 & 27,6 & 754.373 \\
\hline & $\begin{array}{l}\text { Republica } \\
\text { Domini- } \\
\text { cana }\end{array}$ & 195 & 82,1 & 20.851 & 82,5 & 7.919 & 82,5 & 1.954 & 83,3 & 603 & 83,6 & 546 & 84 & 32.068 \\
\hline \multicolumn{2}{|c|}{ TOTAL (03 Países) } & 179.574 & & 361.162 & & 120.412 & & 60.944 & & 28.432 & & 36.591 & & 787.115 \\
\hline \multirow{3}{*}{$\begin{array}{l}\text { América } \\
\text { Norte }\end{array}$} & Canadá & 2 & 99,8 & 9 & 99,8 & 0 & 99,8 & 1 & 99,8 & 4 & 99,8 & 3 & 99,8 & 19 \\
\hline & EUA & 15 & 99,9 & 42 & 100 & 18 & 100 & 14 & 100 & 14 & 100 & 4 & 100 & 107 \\
\hline & México & 1 & 82,3 & 1 & 83 & 2 & 83,7 & 187 & 84,4 & 14 & 85,1 & 1 & 85,2 & 206 \\
\hline \multicolumn{2}{|c|}{ TOTAL (03 Países) } & 18 & & 52 & & 20 & & 202 & & 32 & & 8 & & 332 \\
\hline & Chile & 0 & 97,7 & 1 & 98,3 & 0 & 98,8 & 2 & 99 & 24 & 99 & 0 & 99,1 & 27 \\
\hline & Venezuela & 0 & 93 & 49 & 93,5 & 0 & 94 & 4 & 94,4 & 0 & 94,4 & 0 & 94,4 & 53 \\
\hline \multicolumn{2}{|c|}{ TOTAL (02 Países) } & 0 & & 50 & & 0 & & 6 & & 24 & & 0 & & 80 \\
\hline \multirow{2}{*}{$\begin{array}{l}\text { Ásia Cen- } \\
\text { tro Oriental }\end{array}$} & China & 157 & 70,8 & 26 & 71,9 & 77 & 73,1 & 53 & 74,2 & 24 & 75,4 & 13 & 76,5 & 350 \\
\hline & Japão & 0 & 100 & 12 & 100 & 3 & 100 & 8 & 100 & 10 & 100 & 7 & 100 & 40 \\
\hline \multicolumn{2}{|c|}{ TOTAL (02 Países) } & 157 & & 38 & & 80 & & 61 & & 34 & & 20 & & 390 \\
\hline \multirow{3}{*}{$\begin{array}{l}\text { Ásia Meri- } \\
\text { dional }\end{array}$} & lêmen & 300 & 52,7 & 31.789 & 53 & 0 & 53,3 & 0 & 53,1 & 0 & 52,9 & 0 & 52,8 & 32.089 \\
\hline & Irã & 0 & 88,6 & 1.187 & 89,3 & 53 & 89,6 & 256 & 89,9 & 0 & 89,9 & 86 & 90 & 1.582 \\
\hline & Iraque & 2 & 83,3 & 127 & 84 & 4.693 & 84,8 & 1 & 85,6 & 0 & 85,6 & 4.965 & 85,6 & 9.788 \\
\hline \multicolumn{2}{|c|}{ TOTAL (03 Países) } & 302 & & 33.103 & & 4.746 & & 257 & & 0 & & 5.051 & & 43.459 \\
\hline \multirow[t]{9}{*}{$\begin{array}{l}\text { Ásia Su- } \\
\text { deste }\end{array}$} & $\begin{array}{l}\text { Afeganis- } \\
\text { tão }\end{array}$ & 2.369 & 29,3 & 3.733 & 29,9 & 12 & 30,5 & 3.957 & 31,1 & 45.481 & 31,8 & 58.064 & 31,9 & 113.616 \\
\hline & Camboja & 588 & 33,6 & 0 & 35,4 & 0 & 37,2 & 0 & 39 & 0 & 40,8 & 0 & 42,4 & 588 \\
\hline & Filipinas & 33 & 70,5 & 120 & 71,1 & 1.864 & 71,8 & 6 & 72,5 & 4.547 & 73,2 & 0 & 73,9 & 6.570 \\
\hline & Índia & 5.155 & 35,5 & 0 & 36,5 & 0 & 37,5 & 6.008 & 38,5 & 4.031 & 39,5 & 889 & 39,6 & 16.083 \\
\hline & Malásia & 443 & 95,4 & 586 & 95,7 & 282 & 95,9 & 171 & 96 & 189 & 96 & 244 & 96 & 1.915 \\
\hline & Mianmar & 95 & 76,6 & 19 & 78 & 174 & 79,4 & 33 & 79,5 & 400 & 79,5 & 103 & 79,6 & 824 \\
\hline & Nepal & 1.790 & 37,9 & 12 & 39,5 & 34 & 41,1 & 0 & 42,6 & 993 & 44,2 & 80 & 45,8 & 2.909 \\
\hline & Paquistão & 164 & 54,8 & 527 & 56,5 & 144 & 58,3 & 1.069 & 60 & 1.218 & 61,8 & 0 & 63,5 & 3.122 \\
\hline & $\begin{array}{l}\text { República } \\
\text { Democráti- } \\
\text { ca do Laos }\end{array}$ & 237 & 58,7 & 0 & 61,7 & 0 & 61,7 & 0 & 67,6 & 0 & 70,5 & 0 & 70,9 & 237 \\
\hline
\end{tabular}


Tabela 1. (cont.)

\begin{tabular}{|c|c|c|c|c|c|c|c|c|c|c|c|c|c|c|}
\hline \multirow{2}{*}{\multicolumn{2}{|c|}{$\begin{array}{l}\text { Tailândia } \\
\text { Vietnã }\end{array}$}} & 1.974 & 93,3 & 279 & 93,3 & 12 & 93,2 & 8 & 93,1 & 12 & 93 & 125 & 93 & 2.410 \\
\hline & & 606 & 69,7 & 3 & 71,4 & 0 & 73,1 & 0 & 74,7 & 0 & 76,3 & 0 & 78 & 609 \\
\hline \multicolumn{2}{|c|}{ TOTAL (11 Países) } & 13.454 & & 5.279 & & 2.522 & & 11.252 & & 56.871 & & 59.505 & & 148.883 \\
\hline \multirow{2}{*}{$\begin{array}{l}\text { Europa } \\
\text { Central }\end{array}$} & Inglaterra & 8 & 99,2 & 32 & 99,2 & 17 & 99,2 & 6 & 99,2 & 14 & 99,2 & 15 & 99,2 & 92 \\
\hline & Ucrânia & 0 & 95,6 & 33 & 95,7 & 0 & 95,8 & 0 & 95,8 & 0 & 95,9 & 0 & 95,9 & 33 \\
\hline \multicolumn{2}{|c|}{ TOTAL (02 Países) } & 8 & & 65 & & 17 & & 6 & & 14 & & 15 & & 125 \\
\hline \multirow[t]{2}{*}{ Oceania } & Austrália & 3 & 100 & 6 & 100 & 5 & 100 & 3 & 100 & 4 & 100 & 2 & 100 & 23 \\
\hline & $\begin{array}{l}\text { Papua } \\
\text { Nova } \\
\text { Guiné }\end{array}$ & 8.997 & 19 & 1.535 & 18,9 & 0 & 18,9 & 0 & 18,9 & 0 & 18,9 & 0 & 18,9 & 10.532 \\
\hline \multicolumn{2}{|c|}{ TOTAL (02 Países) } & 9.000 & & 1.541 & & 5 & & 3 & & 4 & & 2 & & 10.555 \\
\hline \multicolumn{2}{|c|}{ TOTAL (58 Países) } & 316.665 & & 588.256 & & 245.335 & & 129.053 & & 215.440 & & 172.308 & & 1.667 .057 \\
\hline
\end{tabular}

Fonte: Adaptado de WHO25 e World Bank 26 .

Ano de 2010. Foram registrados 316.665 casos da doença em 43 países, com destaque para a região da América Centro-caribenha, com 179.574 ocorrências, 179.379 dos quais ocorreram no Haiti. A região da África Centroatlântica apresentou 59.770 casos, com destaque para a Nigéria, com 44.456 casos. Os países da África Central somaram 33.738 acometimentos, dos quais 13.884 foram registrados na República Democrática do Congo. Foram registrados 13.454 casos do Ásia Sudeste, sendo 5.155 somente na Índia, nove mil na Oceania, e 8.977 casos em Papua Nova Guiné (gráfico 1).

Quanto ao AS, dos 43 países que registraram casos de cólera, 27 contavam com menos de $50 \%$ de AS, com destaque para o Afeganistão (Ásia Sudeste), Haiti (América Centro-caribenha), Papua Nova Guiné (Oceania), Chade, Etiópia, Níger, Uganda, República Democrática do Congo (África Central). Costa do Marfim, Gana, Libéria e Togo (África Centro-atlântica), Quênia, Moçambique, Somália e Tanzânia registraram níveis inferiores a $30 \%$ para este indicador. Nos países com casos de cólera mais expressivos no período analisado (barras aparentes no gráfico 1), a relação IC e AS sugere uma relação inversamente proporcional. Com alta incidência de casos e acesso a saneamento aparecem a Tailândia (AS=93,3\% e IC $=1.974)$ e Malásia ( $\mathrm{AS}=95,4 \%$ e $\mathrm{IC}=443$ ). 
Gráfico 1. Incidência de Cólera (IC) e Acesso ao Saneamento (AS) no ano de 2010

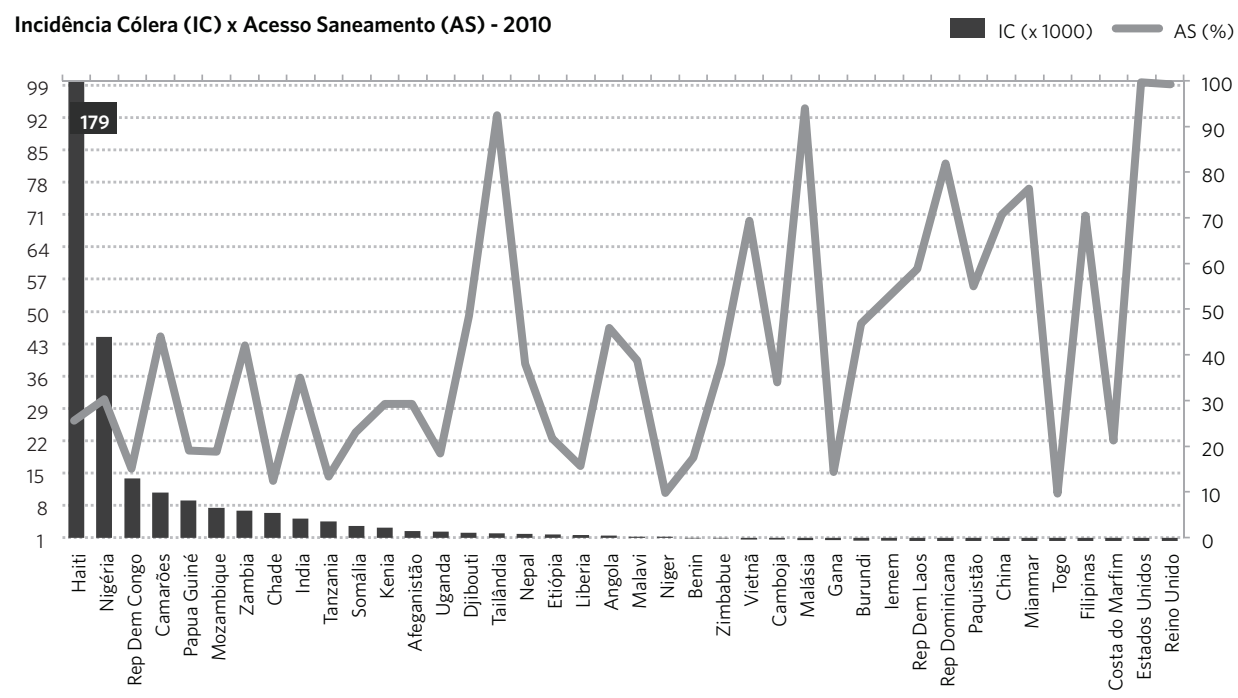

Fonte: Adaptado de $\mathrm{WHO}^{25}$ e World Bank26.

De acordo com os dados da análise de correlação para o período, este índice foi negativo nas regiões da África Central ( $\mathrm{r}=-0,076)$, da África Índica $(r=-0,48)$, na América Centro-caribenha $(r$ = -0,990), na Ásia Meridional ( $\mathrm{r}=-0,991)$ e na Ásia Central ( $\mathrm{r}=-0,438)$; e foi positiva para as demais regiões, sendo $r=0,29$ na África Centro-atlântica e r=0,55 na América do Norte.

Ano de 2011. No ano de 2011, foram registrados 588.262 casos da doença (aumento de 46,17\% em comparação com 2010) em 48 países. A região da América Centro-caribenha registrou 361.162 casos, sendo 340.311 no Haiti; a África Índica teve 79.931 acometimentos, sendo 77.636 na Somália. Países da região da África Centro-atlântica registraram 61.865 casos, do a quais 23.377 ocorreram na Nigéria. A África Central com 45.170 registros, sendo 21.700 na República Democrática do Congo. A Ásia Meridional registrou 33.103, e o maior representante foi o Iêmen, com
31.789 ocorrências. Na Ásia Sudeste ocorreram 5.279 casos, sendo 3.733 no Afeganistão, e 1.541casos foram registrados na região da Oceania, dos quais ocorreram somente em Papua Nova Guiné (gráfico 2). Dos 48 países com casos de cólera, 28 registraram AS abaixo de 50\%: Afeganistão (Ásia Sudeste), Haiti (América Centro-caribenha), Papua Nova Guiné (Oceania), Burkina Faso, Chade, Máli, Níger, República Centro-africana, República Democrática do Congo (África Central), Benin, Congo, Costa do Marfim, Gana, Guiné, Libéria. Apresentaram AS abaixo de 30\% Togo (África Centro-atlântica), Quênia, Moçambique, Somália e Tanzânia (África Índica). A relação entre o IC e o AS sugere o mesmo padrão do ano anterior. Alta incidência e acesso a saneamento foram registrados na Malásia (AS=95,7\% e IC=586), na Tailândia (AS=93,3\% e IC=279), no Irã (AS=89,3\% e IC=20.581) e na República Dominicana $(\mathrm{AS}=82,1 \%$ e IC=20.850). 
Gráfico 2. Incidência de Cólera (IC) e Acesso ao Saneamento (AS) no ano de 2011

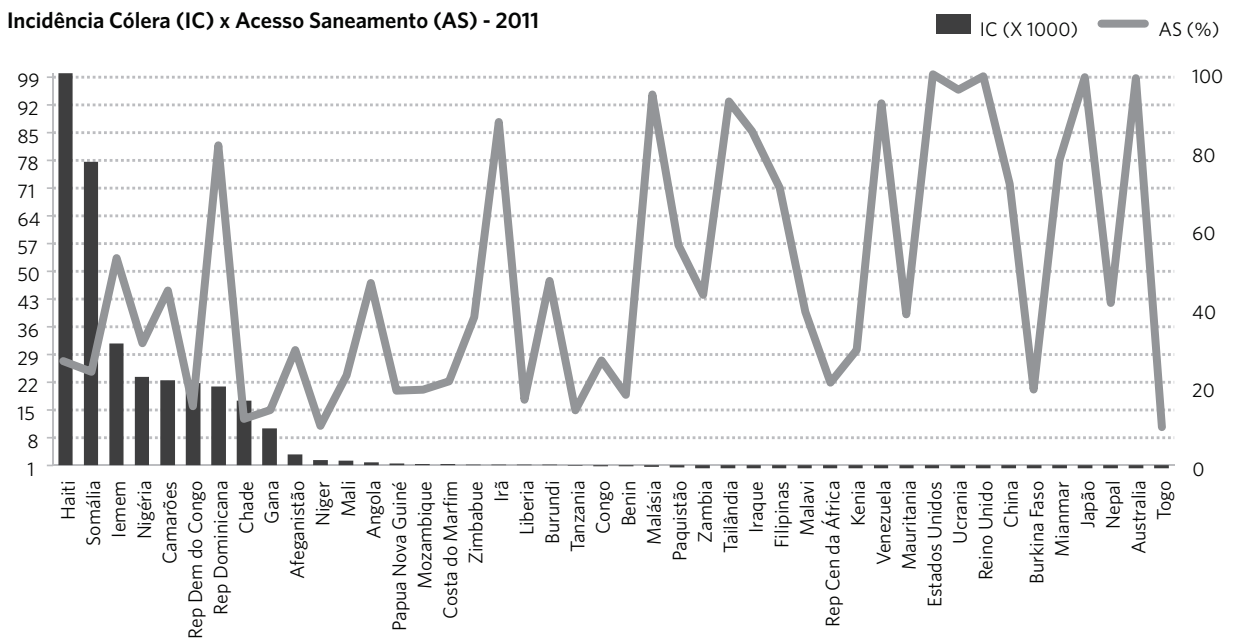

Fonte: Adaptado de $\mathrm{WHO}^{25}$ e World Bank 26

No que se refere à correlação entre as variáveis, observou-se uma correlação negativa para América Centro-caribenha $(\mathrm{r}=-0,996)$, Ásia Meridional ( $\mathrm{r}=-0,986)$, e Ásia Sudeste $(r=-0,337)$. As demais regiões apresentaram correlação positiva: África Central $(\mathrm{r}=0,415)$, África Índica $(\mathrm{r}=0,194)$, América do Norte $(\mathrm{r}=0,658)$. Entretanto para a África Centro Atlântica não houve correlação.

Ano de 2012. Em 2012, foram notificados 245.335 casos de cólera em 46 países (queda de $47,40 \%$ na comparação com 2011). A região da América Centro-caribenha registrou 120.412 ocorrências, sendo 112.076 somente no Haiti; África Centro-atlântica registrou 47.775, sendo 23.124 em Serra Leoa. A região da África Central teve 46.253 notificações, sendo 33.661 somente na República Democrática do Congo; E ainda 23.505 casos na África Índica, sendo 22.572 na Somália; 4.746 na Ásia Meridional, sendo 4.693 no Iraque; Ásia sudeste teve 2.522 registros, sendo 1.864 nas Filipinas. No mesmo período, dos 46 países analisados, 27 não atingiram $50 \%$ de AS. Para Haiti (América Centro-caribenha), Burkina Faso, Máli, Níger, República Central-africana, República Democrática do Congo, Uganda (África Central), Gana, Guiné, Guiné-Bissau,
Libéria, Nigéria, Serra Leoa, Togo (África Centroatlântica), Moçambique, Somália e Tanzânia, o AS ficou abaixo de $30 \%$. A relação entre IC e AS manteve a tendência dos anos anteriores. Malásia (AS=95,9\% e IC=282), $\mathrm{Cuba}(\mathrm{AS}=92,7 \%$ e IC=417), Iraque ( $\mathrm{AS}=84,8 \%$ e IC=4.693) e República Dominicana ( $\mathrm{AS}=82,5 \%$ e IC=7.919) são os casos de países com altos índices de saneamento que registraram ocorrências de cólera.

A correlação entre as variáveis foi negativa para África Central ( $\mathrm{r}=-0,273)$, África Centro-atlântica ( $\mathrm{r}=-0,405)$ e América Centrocaribenha $(r=-0,996)$. As outras regiões apresentaram correlação positiva: África Índica $(\mathrm{r}=0,167)$, América do Norte $(\mathrm{r}=0,419)$, Ásia Meridional ( $r=0,399)$ e Ásia Sudeste $(r=0,237)$.

Ano de 2013. Em 2013, registraram-se em 41 países, 129.053 casos de cólera - uma queda de $40,63 \%$ em comparação com o ano anterior. A região da América Centro caribenha registrou 60.944 ocorrências, sendo 58.809 somente no Haiti; 29.857 casos na região da África Central, dos quais 26.944 ocorreram na República Democrática do Congo. AÁfrica Centro-atlântica registrou 17.462 acometimentos de cólera, sendo 6.600 na Nigéria; A Ásia Sudeste teve 11.252 notificações, sendo 6.008 somente na Índia; e 9.003 
casos ocorreram na região da África Índica, sendo 6.894 na Somália. Quanto ao saneamento, dos 41 países com notificação de cólera, 22 apresentaram $\mathrm{AS}$ abaixo de $50 \%$. O índice de AS foi inferior a 30\%: em alguns países de algumas regiões na África Central (Níger, República Democrática do Congo, Uganda e Mali) na África Centroatlântica (Togo, Serra Leoa, Gana, Libéria, Benin, Guiné, Guiné-Bissau, Costa do Marfim, Congo e Nigéria); na África Índica (Tanzânia, Moçambique e Somália); e na América Centrocaribenha (Haiti). No tocante à análise entre os indicadores IC e AS, no período de 2013, manteve-se a mesma relação dos três anos anteriores, quando foram registrados altos índices de saneamento e de incidência: Malásia (AS $=95,9 \%$ e IC=282), Cuba ( $\mathrm{AS}=92,7 \%$ e IC=417), Iraque (AS=84,8\% e IC=4.693) e República Dominicana (AS=82,5\% e IC=7.919).

A correlação foi negativa na África Central $(\mathrm{r}=-0,187)$, na América Centro-caribenha $(\mathrm{r}=-$ 0,993), na América do Norte $(r=-0,997)$ e no Ásia Sudeste $(\mathrm{r}-=0,589)$. A correlação positiva foi observada na África Centro-atlântica $(\mathrm{r}=0,503)$, na África Índica $(\mathrm{r}=0,075)$ e na Ásia Meridional $(\mathrm{r}=0,592)$.
Ano de 2014. Foram notificados em 2014 215.440 casos de cólera em 37 países - um aumento de 40,10\% em comparação com ano anterior. A região da África Centro-atlântica registrou 69.893 ocorrências, sendo 35.996 na Nigéria; no Ásia Sudeste houve 56.871 ocorrências, sendo 45.481 no Afeganistão; a África Central registrou 31.601 acometimentos, sendo 22.230 na República Democrática do Congo; a África Índica notificou 28.535 casos, sendo 28.020 na Somália; na América Centro-caribenha foram registrados 28.432 casos, sendo 27.753 no Haiti (gráfico 3). Em relação ao AS, dos 37 países analisados, 21 países apresentaram AS abaixo de 50\%. Registraram esse índice abaixo de 30\% Sudão do Sul, Níger, República Democrática do Congo e Uganda (situados na região da África Central); Togo, Gana, Libéria, Benin, Guiné, Guiné-Bissau, Costa do Marfim e Nigéria (na África Centro-atlântica); Moçambique, Somália (na África Índica) e Haiti (na América Centro-caribenha). Nos países com valores de IC mais expressivos, a relação entre os indicadores manteve tendências anteriores, com $\mathrm{AS}=83,6 \%$ e IC=603, sendo que a República Dominicana registrou valores elevados para os dois indicadores.

Gráfico 3. Incidência de Cólera (IC) e Acesso ao Saneamento (AS) no ano de 2014

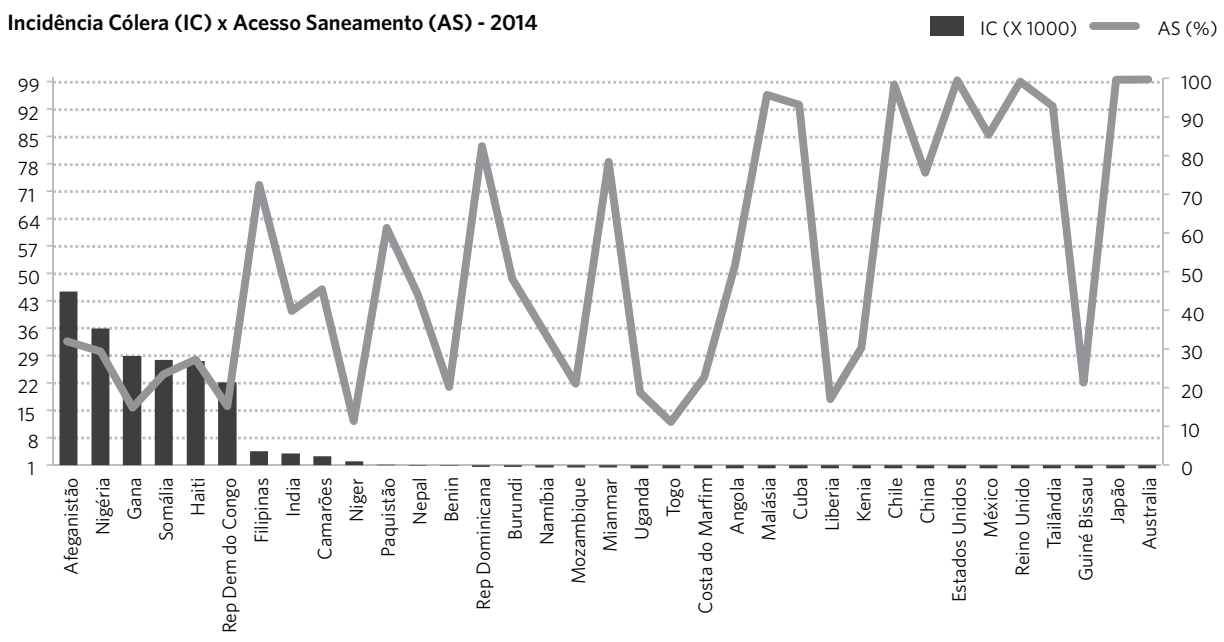

Fonte: Adaptado de $\mathrm{WHO}^{25}$ e World Bank26 
Durante esse período, apenas a região que da África Índica apresentou correlação positiva, com $r=0,13$. Na Ásia Meridional não houve correlação entre os dados, e as demais regiões tiveram correlações negativas: África Central ( $r=-0,342)$, África Centro-atlântica $(\mathrm{r}=-0,06)$, América Centro-caribenha ( $\mathrm{r}=-$ 0,992), América do Norte ( $\mathrm{r}=0,489$ e Ásia Sudeste $(r=-0,515)$.

Ano de 2015. No último ano de observação, foram registradas 172.308 ocorrências de cólera em 32 países - uma redução de 20,02\% de casos em comparação a 2014. A região do Ásia Sudeste registrou o maior número de ocorrências da doença, com 59.505 casos, sendo 58.064 no Afeganistão. A África Índica registrou 41.129 acometimentos, sendo 13.291 no Quênia. A América Centro-caribenha registrou 36.591 casos, sendo 36.045 no Haiti; a região da África Central notificou 23.647 casos, dos quais 19.182 foram registrados na República Democrática do Congo; e a África Centro-atlântica registrou 6.340 acometimentos, sendo 5.290 na Nigéria (gráfico 4). Em 2015, 19 dos 32 países analisados registraram menos que $50 \%$ de AS. Índices inferiores a $30 \%$ de AS foram registrados para Sudão do Sul, Níger, República Democrática do Congo e Uganda (região da África Central); Togo, Gana, Costa do Marfim e Nigéria (região da África Centro-atlântica); Tanzânia, Moçambique, Somália (África Índica); e Haiti (América Centro-caribenha). Entre os países com IC mais expressivos, a relação entre os indicadores, manteve-se mais uma vez dentro do padrão esperado, repetindo a tendência de todos os anos anteriores. Altos índices de saneamento e de incidência foram registrados no Iraque $(\mathrm{AS}=85,6 \%$ e IC=4.965) e na República Dominicana $(\mathrm{AS}=84$ e IC=546).

Gráfico 4. Incidência de Cólera (IC) e Acesso ao Saneamento (AS) no ano de 2015

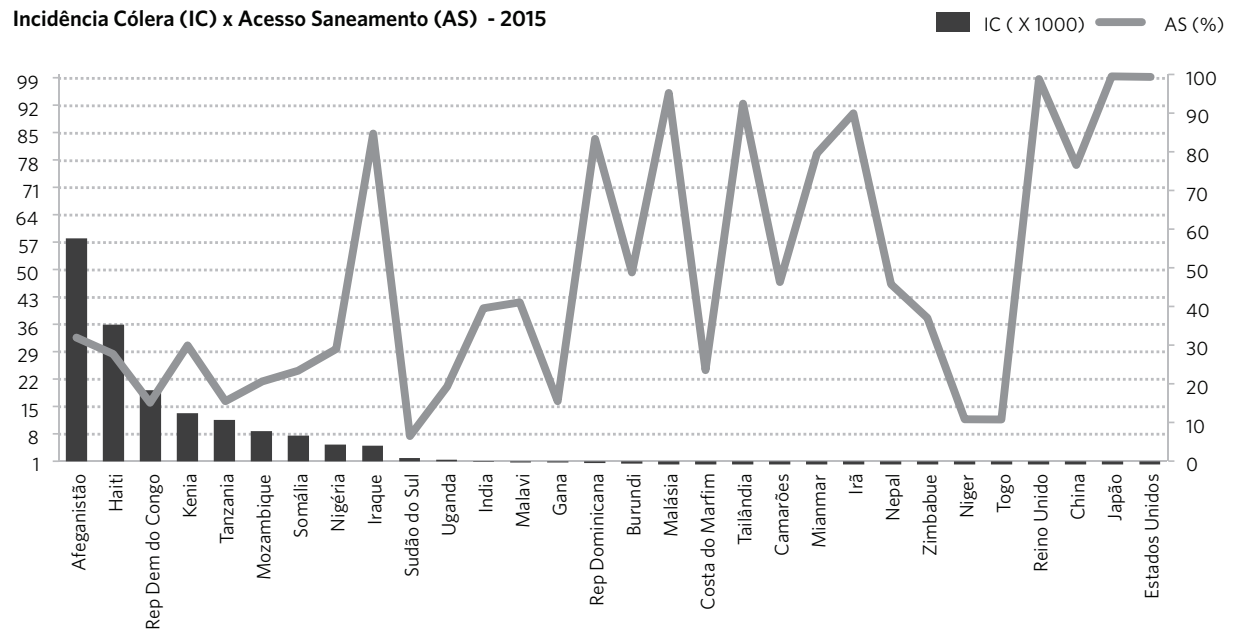

Fonte: Adaptado de $\mathrm{WHO}^{\mathbf{2 5}}$ e World Bank $\mathbf{2 6}$ 
Por fim, em 2015, as correlações negativas só foram observadas nas regiões da África Central $(\mathrm{r}=-0,237)$, da América Centro-caribenha ( $\mathrm{r}=-$ 0,993), e do Ásia Sudeste ( $\mathrm{r}=-0,501)$. As demais obtiveram correlação positiva: África Centroatlântica $(\mathrm{r}=0,05)$, África Índica $(\mathrm{r}=0,301)$, América do Norte ( $\mathrm{r}=0,948)$ e Ásia Meridional $(r=0,417)$.

\section{Discussão}

Os resultados apresentados neste trabalho indicam o quanto o Saneamento Básico é importante e fundamental para a saúde humana. De acordo com Heller ${ }^{28}$, a relação entre saúde e saneamento é vital no contexto da prevenção de agravos à humanidade. Ainda segundo o autor, a problemática do saneamento encontra-se fortemente associada ao modelo econômico, que excluídos benefícios do desenvolvimento a parcela da população mais vulnerável.

A inacessibilidade a recursos ocasionada pela posição de um grupo abaixo da linha de pobreza, e outro acima, determina a instalação de desigualdades absolutas, enquanto desigualdades dentro de um mesmo grupo social ocasionam desigualdades relativas, as quais, em saúde, podem ser descritas em duas vertentes: (i) aquelas que se referem ao perfil patológico da população, fortemente relacionadas pela organização social e pela inserção do indivíduo na mesma; e (ii) aquelas que se referem à oferta de serviços, que são mais fortemente influenciadas pela política nacional da saúde, as quais poderão ser reduzidas ou eliminadas por meio de sistemas universais ${ }^{29}$.

A proximidade da relação entre saúde e ambiente traça duas linhas complementares: no olhar da saúde, acaba por valorizar o ambiente como fator determinante de agravos à saúde; e sob a ótica do ambiente, vislumbra as alterações, em si próprio, como agente ativo deste circuito $^{28}$.

A interatividade entre ambiente e saúde é reforçada quando a doença infecciosa é considerada emergente ou recorrente, devido à íntima relação entre o meio ambiente e condições de saneamento básico insatisfatórias. Neste contexto, há uma relação diretamente proporcional entre problemas sociais e degradação ambiental e, consequentemente, maior risco do surgimento de doenças infectocontagiosas ${ }^{29}$.

Os países africanos experimentam historicamente grave vulnerabilidade quanto às doenças infectocontagiosas, principalmente por sua frágil situação socioambiental ${ }^{25}$. O continente registrou alta incidência em todas as sete pandemias de cólera ${ }^{30}$. Segundo Mengel et al. ${ }^{31}$, a região apresentou muitas condições agravantes, que influenciaram episódios epidêmicos de cólera, tais como mecanismos impulsionadores de contaminação inicial, fragilidade de resiliência humana e mecanismos eficientes de propagação do agravo.

Nos períodos analisados no estudo, o continente africano foi a região com a maior interação entre os indicadores analisados: 678.879 casos de cólera ( $40,7 \%$ de todos os casos mundiais), devido a gravíssimos problemas de AS - aproximadamente $86 \%$ da população com $\mathrm{AS}>50 \%$, e precária disponibilidade de serviços básicos, geralmente em situações de conflito armado, exploração de riquezas e gestão política em decadência ${ }^{32}$.

Além de todas as formas de transmissão da cólera, a bactéria pode viajar globalmente no intestino de pessoas assintomáticas, o que dificulta a determinação exata dos locais de origem ${ }^{33}$. No entanto, segundo Rosen ${ }^{34}$, os primeiros registros da cólera datam de 400 A.C. a 500 A.C., com origem na Ásia, mais especificamente na Índia, ocorrendo sua propagação em rituais hindus nas águas do Ganges.

Entre os indicadores estabelecidos, os resultados obtidos no continente asiático sugerem uma reflexão de endemismo da patologia, como preconizado por Rosen ${ }^{34}$, e chamam atenção para a importância da análise de outros indicadores de vulnerabilidade. A região apresentou IC alto (192.760 registros) com cerca de 63\% dos países analisados, registrando AS acima de 
$70 \%$ nos anos observados. No entanto, seguindo a tendência mundial, os países que tiveram os índices mais elevados de IC mantiveram baixos índices de AS.

Os países asiáticos, principalmente da parte sul-sudeste, experimentam severos problemas sociais, como conflitos armados, fome, inexistência de sistema de seguridade social e de saúde, e administração política precária, o que acaba por agravara fragilidade do sistema de prevenção, controle e resposta de problemas de saúde coletiva. Ilustrando esta situação, o Iêmen registrou em 2017 cerca de um milhão de casos de cólera ${ }^{25}$, tornando-se a pior epidemia de cólera já registrada.

O continente americano apresentou 787.890 registros de cólera, perdendo apenas para o continente africano, com AS variando de satisfatório (acima de 70\%) a bom (acima de $80 \%)$. O Haiti, no entanto, que não apresentou relatos pretéritos, mesmo com surtos reportados na região do Caribe no decorrer do século $\mathrm{XIX}^{35}$, impulsionou a região na majoração do número de casos em todo o período da análise. Proporcionalmente, foi o país com situação mais alarmante em incidência (IC igual a 754.373 ), especialmente no ano de $2010^{25}$, quando foi abalado por um terremoto e um furacão, que acabou por comprometer ainda mais as frágeis condições da população ${ }^{36}$.

Nos cinco anos analisados, o país em nenhum momento superou o índice de $28 \%$ de AS, e experimentou problemas sociais e econômicos graves. Este cenário sugere uma reflexão sobre os surtos que acometeram seu vizinho, a República Dominicana, que apresentou 32.068 casos, apesar de revelar índices satisfatórios de saneamento (média de $83 \%$ ) $^{\mathbf{2 5}}$.

Duas hipóteses surgiram para a rápida propagação do surto no Haiti. A primeira delas é o aquecimento global, defendida pelos pesquisadores David Sacks e Rita Colwell ${ }^{37,38}$ e a introdução do vibrião por indivíduos infectados, provenientes de países onde a doença é endêmica, com foco nas tropas da missão de paz das Nações Unidas e em Organizações Não Governamentais ${ }^{39,40}$. Segundo Orata et al.41, a missão da ONU no Haiti contou com a colaboração de soldados provenientes do Nepal. Casos de cólera foram semanas antes da missão ${ }^{\mathbf{4 2}}$,confirmados por Hendriksen et al. ${ }^{33}$, por meio de investigação gênica.

Uma vez que a maior parte dos países do continente Oceânico é formada por ilhas, a conectividade populacional torna-se um pouco mais difícil e, consequentemente, também a propagação da doença. No entanto, a região apresentou IC $=10.541$, sendo que $98 \%$ dos casos foram registrados na Papua Nova Guiné, onde o índice de AS foi inferior a $20 \% \mathrm{em}$ todos os anos de observação. No restante dos países, o AS se manteve quantitativamente em níveis satisfatórios ( $\mathrm{AS}>75 \%$ em todo o período analisado).

As nações europeias não apareceram no total de registro geral da ocorrência de cólera apresentados no presente estudo. A região apresentou condições sanitárias adequadas no que se refere ao acesso à água potável e ao esgotamento sanitário. Segundo a OMS ${ }^{25}$, os 144 registros se deram em função de casos importados - exposição em viagens a locais onde a doença ocorre endemicamente ou por contágio com visitantes estrangeiros.

Quanto às análises de correlação realizadas ao longo de todo o período, os índices apresentaram-se majoritariamente negativos, mostrando a relação entre a cólera e as questões sanitárias.

Entretanto, correlações negativas foram observadas durante o período de 2014 a 2016 na região da América do Norte, que apresentou $\mathrm{AS}=95 \%$ e $\mathrm{IC}=234$. Este fato sugere uma reflexão sobre atribuir a incidência da doença exclusivamente a problemas derivados da questão sanitária da região, fomentando uma significância a outros fatores socioambientais na tentativa de gerar uma visão complexa e mais ampla do problema.

Quando a correlação foi positiva, observamos que esta foi impulsionada pela ausência de casos registrados da doença, ou por serem consideravelmente inferiores aos demais países da região em relação ao índice de saneamento oferecido. 
As regiões da África Centro-meridional, América do Sul, Ásia Centro-oriental, Europa Central e Oceania não tiveram correlações calculadas por estarem agrupadas em menos de três países cada.

\section{Considerações finais}

Ações em melhorias de esgotamento sanitário, qualidade e quantidade de águas servidas, assim como boas práticas de higiene têm-se mantido como medidas eficazes no controle e na prevenção do agravamento em todo o mundo. Nota-se, todavia, que, para uma parte da população mundial, a o acesso aos serviços de saneamento básico ainda é um privilégio, principalmente nos países em desenvolvimento, o que acaba por aumentar a vulnerabilidade a surtos e, assim, aumentar gastos financeiros em ações corretivas de controle da doença. As ações epidemiológicas de controle da cólera não devem ser pautadas somente no saneamento: outros fatores socioambientais podem surgir como explicação - ou elemento sinérgico - da incidência em regiões que apresentam saneamento satisfatório - por exemplo, processos migratórios, contaminação via água de lastro, eventos climáticos, proximidade com regiões endêmico-epidêmicas, entre outros. Assim sendo, ações de prevenção, monitoramento e resposta devem abranger uma análise ampla em determinantes ambientais, direcionada para a realidade de cada região.

Outro fator importante na construção de planos de prevenção e resposta para todas as doenças infecciosas é o mapeamento das incidências e o estabelecimento de relações com determinantes ambientais associativos, e, consequentemente, a construção de metodologias de regionalização para ordenação de investimentos em ações de vigilância.

Por fim, ficou evidente a relação entre condições de AS e a qualidade desse serviço e a incidência da patologia, que extrapola para a maioria das doenças infectocontagiosas. $\mathrm{Na}$ grande maioria dos casos, existe uma relação íntima entre AS e incidência da doença, mas a relação entre os indicadores deve ser observada com cuidado, e sempre de forma criteriosa, avaliando as individualidades de cada espaço geográfico, e lançando mão de outras variáveis para a construção de um melhor diagnóstico do problema.

Assim sendo, a análise destes indicadores se configura de maneira geral, como uma ferramenta essencial e eficaz na elaboração de medidas de vigilância epidemiológica da cólera.

\section{Colaboradores}

Silva ES (0000-0003-1271-947X)* foi idealizador do artigo, escreveu a introdução e a metodologia, e analisou e escreveu os resultados, além da discussão. Oliveira DD (00000003-1771-1645)* fez as análises dos resultados, escreveu a conclusão, resumo e abstract. Lopes AP (0000-0002-3051-4550)* realizou a busca e organização de dados referentes ao AS e ao IC. 


\section{Referências}

1. World Health Organization. Water, Sanitation and Hygiene Link to Health. Genebra: WHO; 2004.

2. Brasil. Lei $\mathrm{n}^{\circ} 11.445$, de 5 de janeiro de 2007. Lei de diretrizes nacionais para o Saneamento Básico. Diário Oficial da União. 11 Jan 2007.

3. Razzolini MTP, Günther WMR. Impactos na saúde das deficiências de acesso a água. Saúde Soc. 2008; 17(1): 21-32.

4. Neri MC. Trata Brasil: Saneamento e Saúde, 2007. Rio de Janeiro: FGV;IBRE; 2008.

5. World Health Organization. Preventing disease through healthy environments: towards an estimate of the environmental burden of disease. Genève: WHO; 2006.

6. Kosek M, Bern C, Guerrant RL. The global burden of diarrhoeal disease, as estimated from studies published between 1992 and 2000. 2003. Bull World Health Organ. 2003; 81(3):197-204.

7. Mathers CD, Lopez AD, Murray CJL. The burden of disease and mortality by condition: data, methods, and results for 2001. 2006. In: Lopez AD, Mathers CD, Ezzati M, et al., editores. Global burden of disease and risk factors. New York: Oxford University Press. 2006. p.45-240.

8. Feachem RG, Bradley DJ, Garelick H, et al. Sanitation and disease. Health aspects of wastewater and excreta management. Chichester: John Wiley \& Sons; 1983.

9. Daniel LA, Brandão CSS, Guimarães JR, et al. Processos de desinfecção e desinfetantes alternativos na produção de água potável. 2001. Rio de Janeiro: RiMa; ABES; 2001.

10. Waddington H, Snilstveit B. Effectiveness and sustainability of water, sanitation, and hygiene interventions in combating diarrhea. Journal Dev Effect. 2000; (1):295-335.
11. Carvalho AI. Determinantes sociais, econômicos e ambientais da saúde. In: Fundação Oswaldo Cruz. A saúde no Brasil em 2030 - prospecção estratégica do sistema de saúde brasileiro: população e perfil sanitário. Rio de Janeiro: Fiocruz; Ipea; Ministério da Saúde; Secretaria de Assuntos Estratégicos da Presidência da República; 2013. p. 19-38. Volume 2.

12. Organização Pan-Americana da Saúde. Saúde nas Américas: 2007. Washington, DF: Opas; 2007.

13. Silveira DR, Milan C, Rosa JV, et al. Fatores de patogenicidade de Vibrio spp. de importância em doenças transmitidas por alimentos. Arq. Inst. Biol. 2016; 83:1-7.

14. Bratlet DH, Azam F. Chitin: Cholerae and competence. Sci. New York. 2005; 310(5755):1824-7.

15. Campos LC, Ferreira EO. Vibrio Cholerae. In: Trabulsi LR, Alterthum F. Microbiologia. 5. ed. São Paulo: Atheneu; 2008. p. 347-354.

16. Martinelli JEM. A associação entre o zooplâncton e o Vibrio cholerae no complexo estuarino de Santos - Bertioga e plataforma adjacente [dissertação]. Universidade de São Paulo; 2007. 151 p.

17. Mai UEH, Shahamat M, Colwell RR. Survival of Heliobacterpyloriin the aquatic environment. In: Menge H, Gregor M, Tytgat GNJ, et al, editores. Heliobacter pylori 1990. Heidelberg: springer; 1991. p. 91-94.

18. Altug G, Gurun S, Cardak M, et al. The occurrence of pathogenic bacteria in some ship's ballast water incoming from various marine regions to the Sea of Marmara, Turkey. Mar Environ Res. 2012; 81:35-42.

19. Figueiredo SCA, Neves-Borges AC, Coelho A. The Neuraminidase gene is present in the non-toxigenic Vibrio cholerae Amazonia strain: a differentallele in comparison to the pandemic strains. Mem. Inst. Oswaldo Cruz. 2005; 100(6):563-569.

20. Rivera IN, Chun J, Huq A, et al. Genotypes associa- 
ted with virulence in environmental isolates of Vibrio cholerae. 2001. Appl Environ Microbiol. 67(6):2421-9.

21. Bennish Ml. Cholerae: Pathophysiology, clinical feature. 1994. In: Waschsmuth Ik, Blake Pa, Olsvik. Vibrio cholerae and cholerae: molecular to global perspectives. Am. Soc. Microb. 1994; (15):229-256.

22. Silva ES, Viana CM, Rivera ING, et al. Verificação de V. cholerae em águas portuárias da cidade do Rio de Janeiro, Brasil: um ensaio metodológico. 2015. Vig. Sanit. Debate. 4(1):13-19.

23. Teixeira JC, Oliveira GS, Viali AM, et al. Estudo do impacto das deficiências de saneamento básico sobre a saúde pública no Brasil no período de 2001 a 2009. Eng. Sanit. Amb. 2014; 19(1):87:96.

24. Medronho RA, Werneck GL, Perez MA. Distribuição das doenças no Espaço e Tempo. In: Medronho RA, Bloch KV, Luiz RB; et al. Epidemiologia. 2. ed. Rio de Janeiro: Atheneu; 2009. p. 83-102.

25. World Health Organization. Cholerae: Number of reported cases [internet]. Genebra; 2017 [acesso em 2018 dez 31]. Disponível em: http://gamapserver.who. int/gho/interactive_charts/cholera/atlas.html.

26. World Bank. Data Bank and Databases [internet]. [acesso em $2018 \mathrm{dez} 6$ ]. Disponível em: http://databank.worldbank.org/.

27. Boueri R, Costa MA. Instituto de Pesquisa Econômica Aplicada. Brasil em Desenvolvimento 2013: estado, planejamento e políticas públicas. 2013. Brasília, DF: Instituto de Pesquisa Econômica Aplicada; 2013.

28. Heller L. Relação entre saúde e saneamento na perspectiva do desenvolvimento. Ciênc. Saúde Colet. 1998; 3(2):73-84.

29. Barata RCB. O desafio das doenças emergentes e a revalorização da epidemiologia descritiva. Rev. Sau Publ. 1997; 31(5):531:537.

30. Hérnadez-Flórez CE, Cáceres-Manrique FM. Cólera se aproxima uma nueva pandemia. Méd. UIS. 2014;
27(2):97-83.

31. Mengel MA, Delrieu I, Heyerdahl L, et al. Cholera Outbreaks in Africa. In: Nair G, Takeda Y, editores. Cholera Outbreaks. Current Topics in Microbiology and Immunology. Heidelberg: Springer; 2014.

32. Gallo F. O silencioso drama da República Democrática do Congo: Narrativas de refúgio em São Paulo. Hades-Unifesp. 2017; (1):1-24.

33. Hendriksen RS, Price LB, Schupp JM, et al. Population genetics of Vibrio cholerae from Nepal in 2010: Evidence on the origin of the Haitian outbreak. Micro Jour. 2011; 2(4):1-9.

34. Rosen G. Uma História da Saúde Pública. 2. ed. São Paulo: Unesp; 2000.

35. Ministeré de La Santé Publique et de La Population. Rapport journalier [internet]. Paris; 2014. [acesso em 2019 jan 28.]. Disponível em: http://mspp.gouv. ht/site/downloads/Rapport\%20Web_07.01_Avec_ Courbes_Departementales.pdf.

36. USA. United States Geological Survey Magnitude 7.0 - Haiti region [internet]. Denver: USGS Earthquake Hazards Program; 2010. [acesso em 2019 fev 1]. Disponível em: https://strongmotioncenter.org/NCESMD/data/haitiregion_12jan2010/eqinfo.htm.

37. Knox R. Earthquake not to blame for the cholera outbreak in Haiti [internet]. National Public Radio. 2010 out 26. [acesso em 2019 jan 28]. Disponível em: http:// www.npr.org/blogs/health/2010/10/26/130832317/ earthquake-had-nothing-to-do-with-cholera-outbreak-haiti.

38. Parker AA. Cholera in Haiti - The Climate connection. Circle of Blue Water news. 2010 nov 11. [acesso em 2019 mar 3]. Disponível em: http://www.circleofblue.org/waternews/2010/world/hold-cholera-in-haiti-the-climate-connection/.

39. Walker S. Haiti: A year in reports. Al Jazeera English. 2011 set 14. [acesso em 2019 out 16]. Disponível em: https://www.aljazeera.com/programmes/aljazeera- 
correspondent/2011/09/2011913144553324479.html.

40. Katz JM. UN probes base as a source of Haiti cholera outbreak [internet]. Associated Press. 2010 out 28. [acesso em 2019 fev 28]. Disponível em: http:// www.thejakartapost.com/news/2010/10/28/un-probes-base-source-haiti-choleraoutbreak.html.

41. Orata FD, Keim OS, Boucher Y. The 2010 Cholera Outbreak in Haiti: How Science Solved a Controversy [internet]. PLoS Pathogens. 2010 abr 3. [acesso em 2019 fev 28]. Disponível em: https://journals. plos.org/plospathogens/article?id=10.1371/journal. ppat.1003967.

42. Maharjan L. Cholera outbreak looms over capital [internet]. The Himalayan Times. 2010 mar 29. [acesso em 2019 jan 5]. Disponível em http://www.thehimalayantimes.com/fullNews.php?headline $=$ Cholera $+o$ utbreak+looms+over+capital\&NewsID $=258974$.

Recebido em 13/03/2019

Aprovado em 16/09/2019

Conflito de interesses: inexistente

Suporte financeiro: não houve 